\title{
Comparison of Proposed Putative Active Conformations of Linear Altered Peptide Ligands of Myelin Basic Protein Epitope 87-99 by Spectroscopic and Modelling studies: The Role of Position 91 and 96 in T-cell Receptor Activation
}

Efthimia D. Mantzourani, Theodore V. Tselios*, Simona Golič Grdadolnik, James A. Platts, Andrea Brancale, George Deraos, John M. Matsoukas, and Thomas M. Mavromoustakos*

\section{Contents}

${ }^{1} \mathrm{H}-\mathrm{NMR}, \mathrm{DQF}-\mathrm{COSY},{ }^{1} \mathrm{H}_{-}{ }^{13} \mathrm{C}$ HSQC,${ }^{1} \mathrm{H}_{-}{ }^{13} \mathrm{C}$ HSQC-TOCSY, TOCSY, and NOESY spectra. S2-S5

Ramachandran map and chi plot for the selected structures after MD runs

Histogram plots of distance and energy data from MD runs

Superimposition between $\mathrm{MBP}_{87-96}$ obtained from the crystal structure and proposed bioactive conformation of $\left[\mathrm{Arg}^{91}, \mathrm{Ala}^{96}\right] \mathrm{MBP}_{87-99}$

Superimposition of proposed bioactive conformations of $\left[\mathrm{Arg}^{91}, \mathrm{Ala}^{96}\right.$ ] $\mathrm{MBP}_{87-99}$ and $\left[\mathrm{Ala}^{91,96}\right.$ ] $\mathrm{MBP}_{87-99}$

Table of intra-residue NOEs

Tables of measured distances for the selected structures after the MD runs

S13-S14 


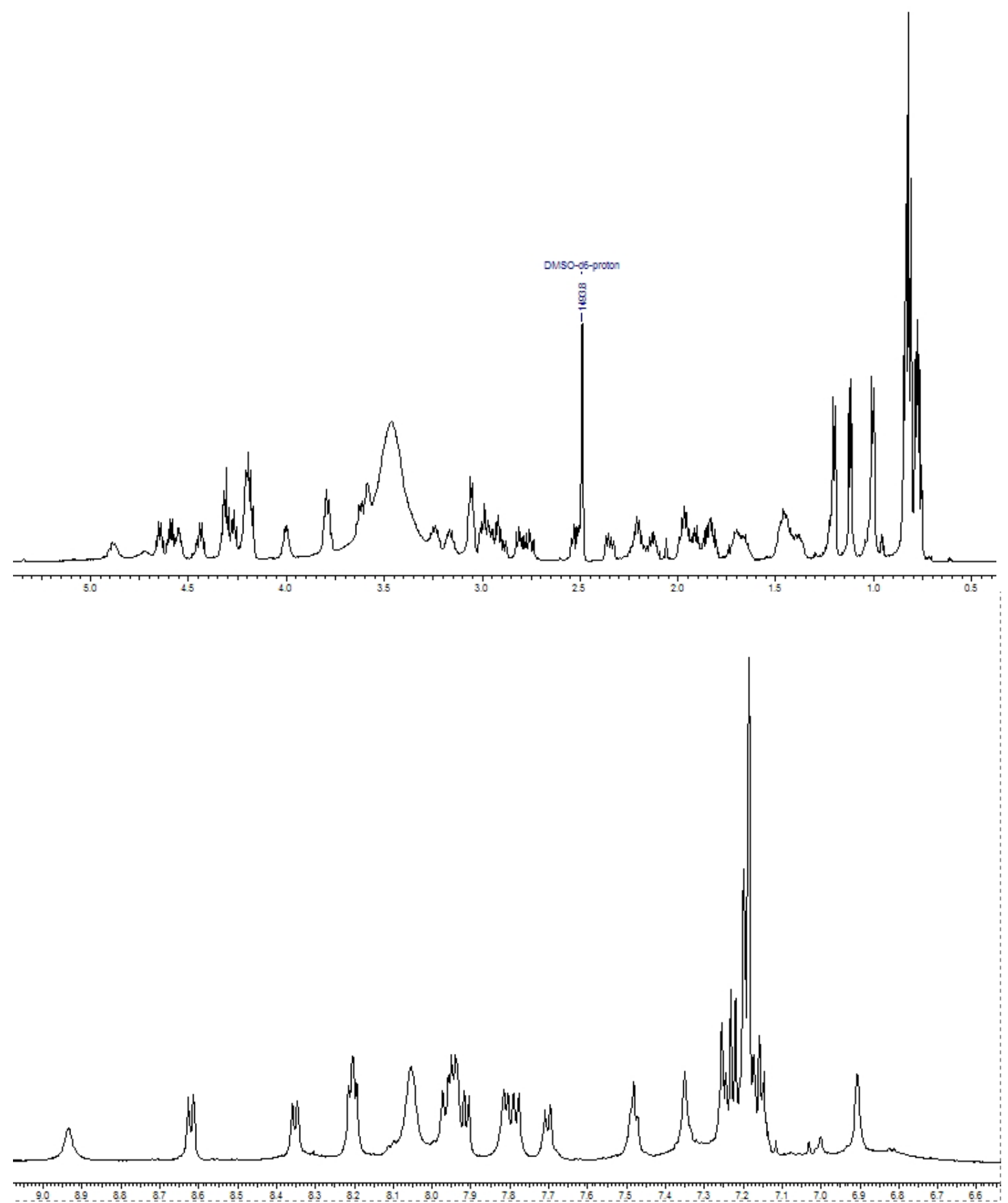

Figure 1: ${ }^{1} \mathrm{H}-\mathrm{NMR}$ spectrum of $\left[\mathrm{Ala}^{91,96}\right] \mathrm{MBP}_{87-99}$ in DMSO- $d_{6}$ recorded on a Varian INOVA 600 $\mathrm{MHz}$ spectrometer 

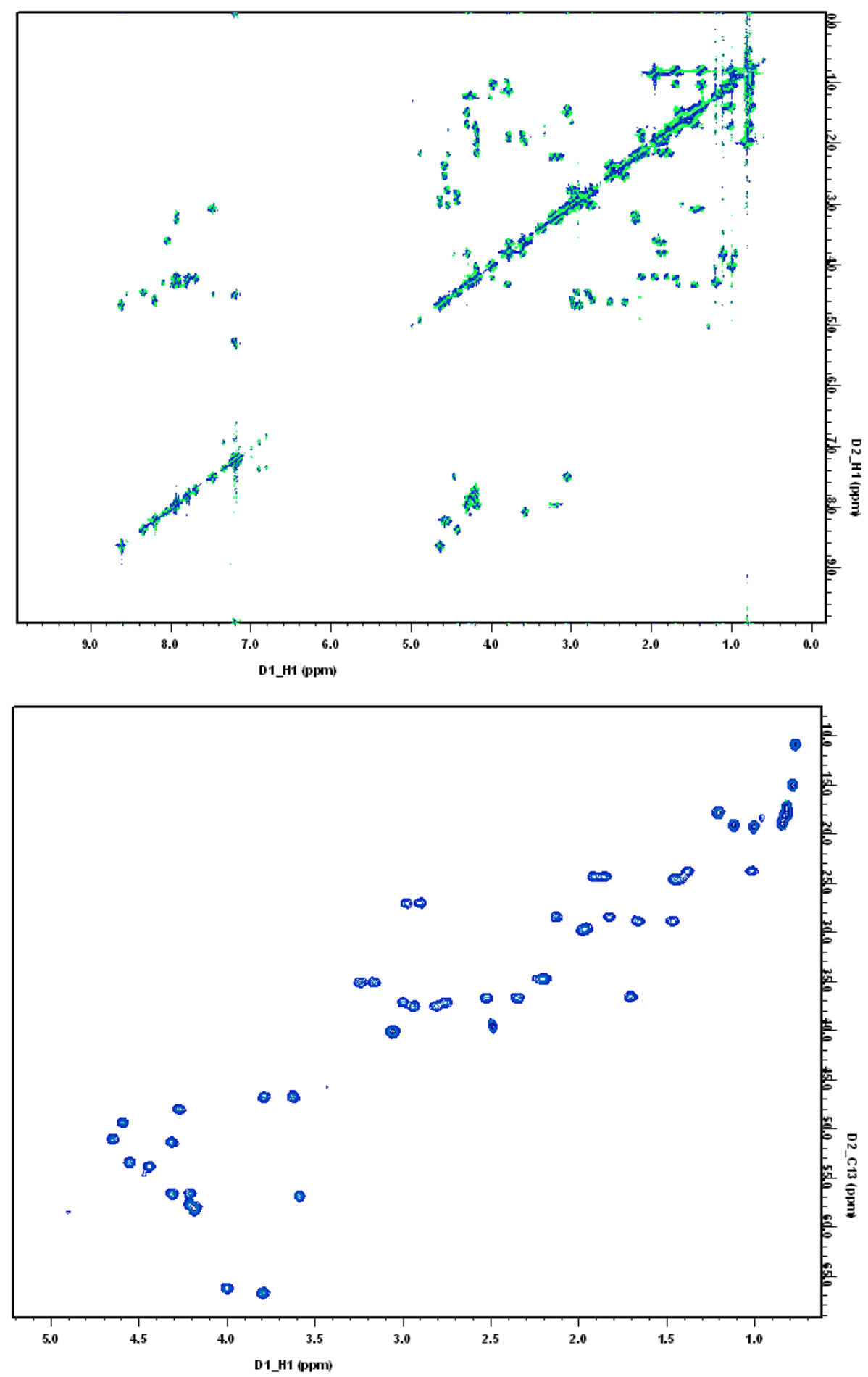

Figure 2: DQF-COSY (up) and ${ }^{1} \mathrm{H}^{13} \mathrm{C}$ HSQC (down) spectra of [Ala $\left.{ }^{91,96}\right] \mathrm{MBP}_{87-99}$ in DMSO- $d_{6}$ recorded on a Varian INOVA $600 \mathrm{MHz}$ spectrometer 

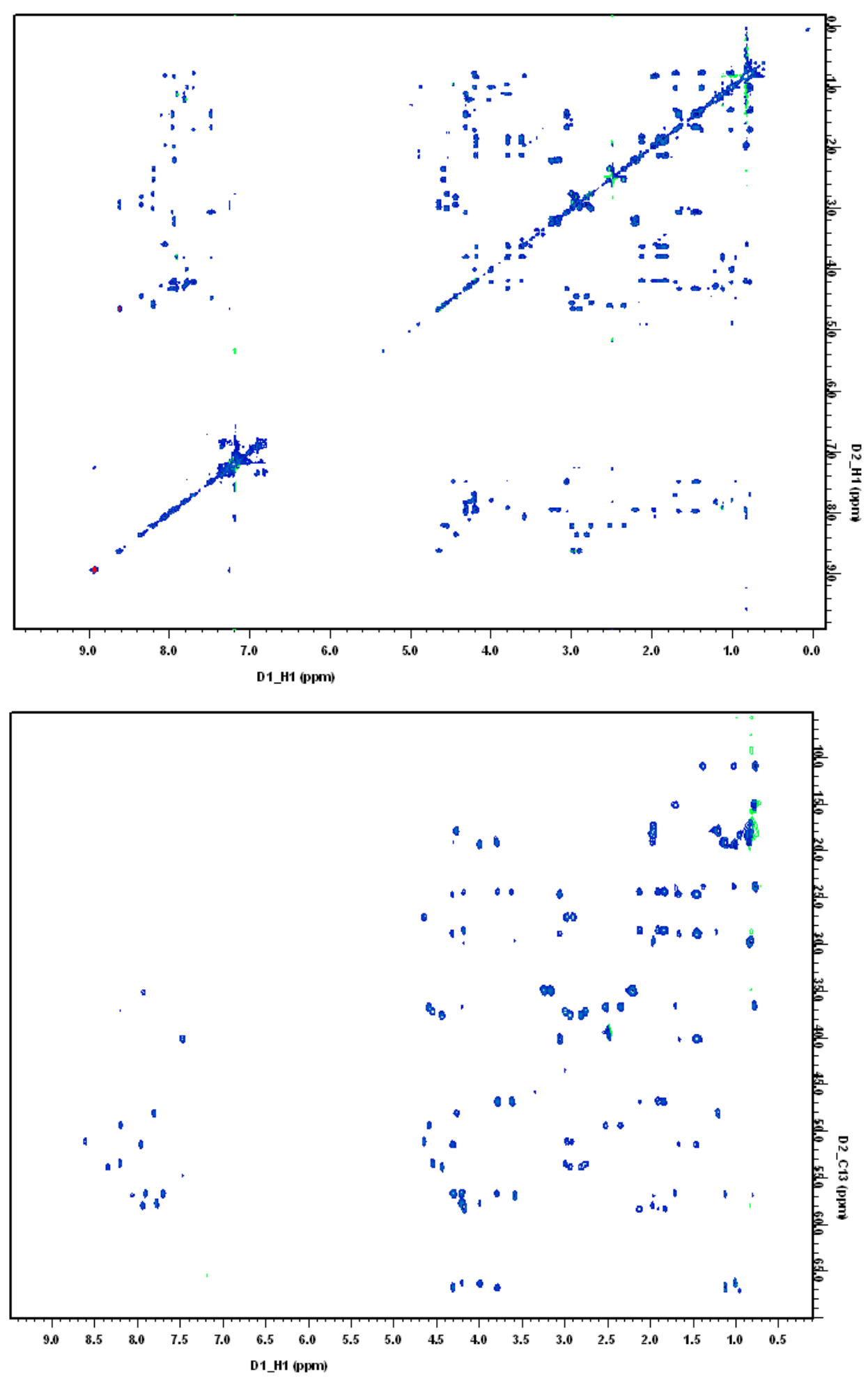

Figure 3: TOCSY (up) and ${ }^{1} \mathrm{H}_{-}{ }^{13} \mathrm{C}$ HSQC-TOCSY (down) spectra of $\left[\mathrm{Ala}^{91,96}\right] \mathrm{MBP} 87-99$ in DMSO- $d_{6}$ recorded on a Varian INOVA $600 \mathrm{MHz}$ spectrometer 


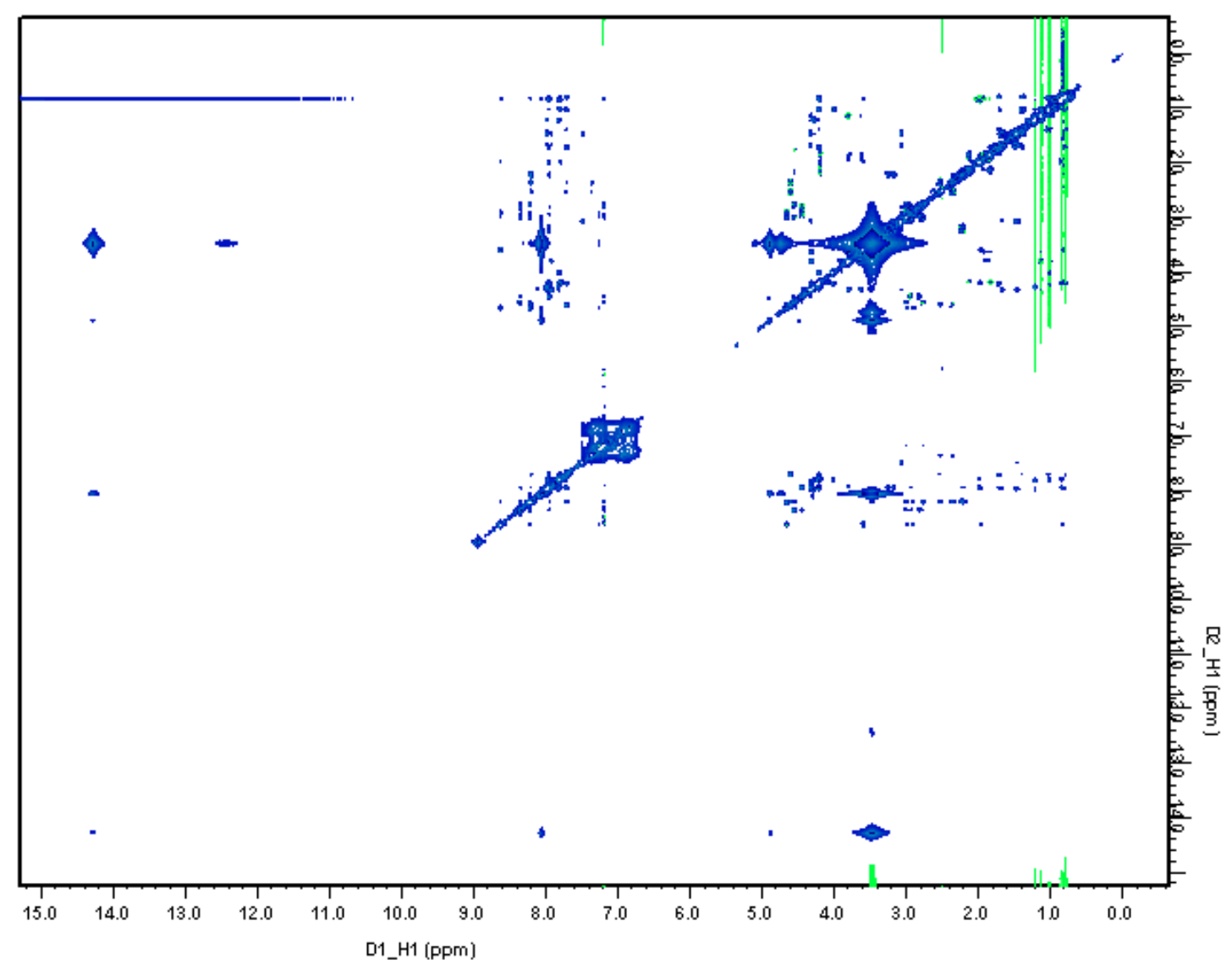

Figure 4: NOESY spectrum of $\left[\mathrm{Ala}^{91,96}\right] \mathrm{MBP}_{87-99}$ in DMSO- $d_{6}$ recorded on a Varian INOVA 600 MHz spectrometer 


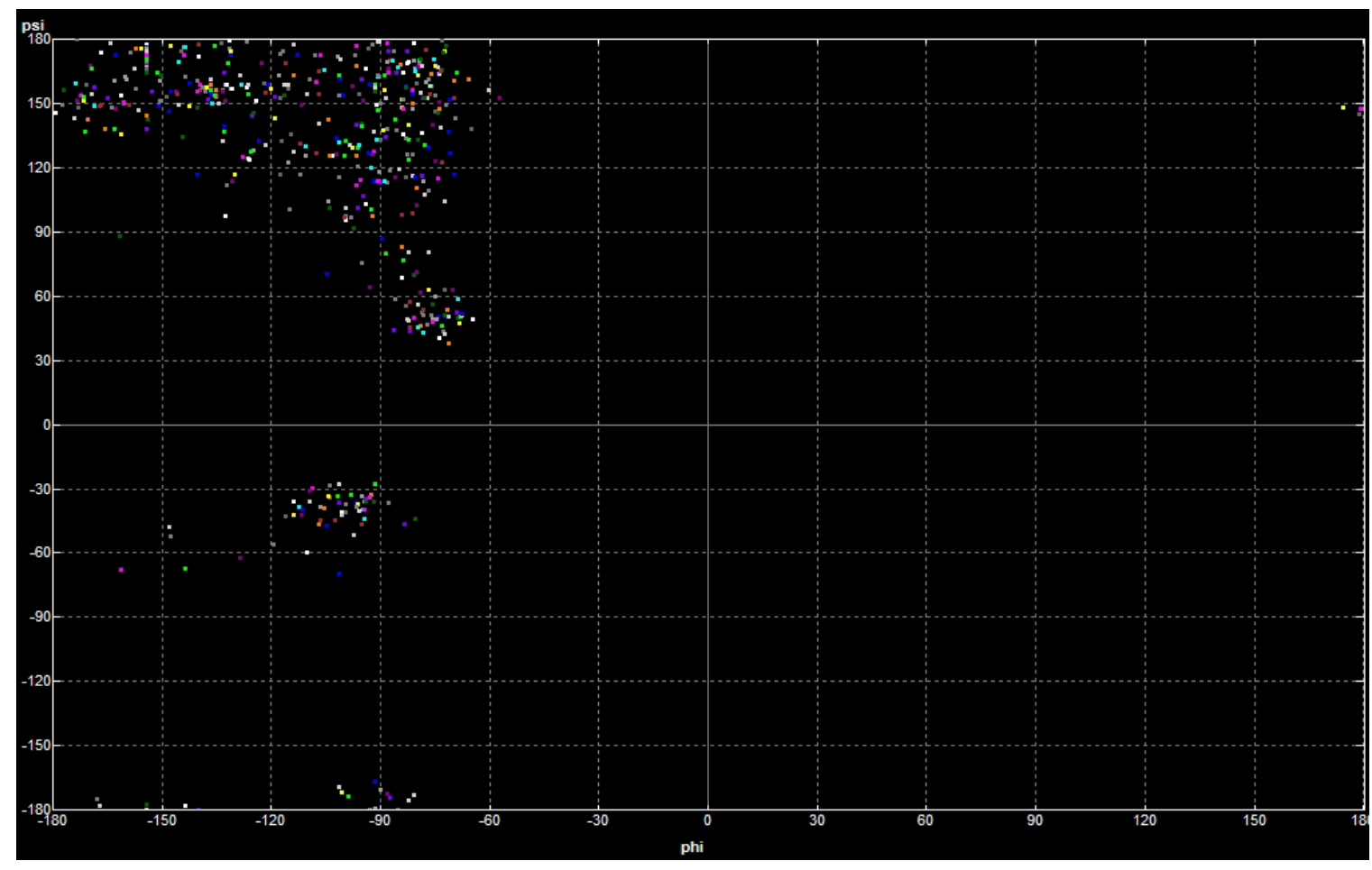

Figure 5: Ramachandran map for the selected low energy conformations of MD runs.

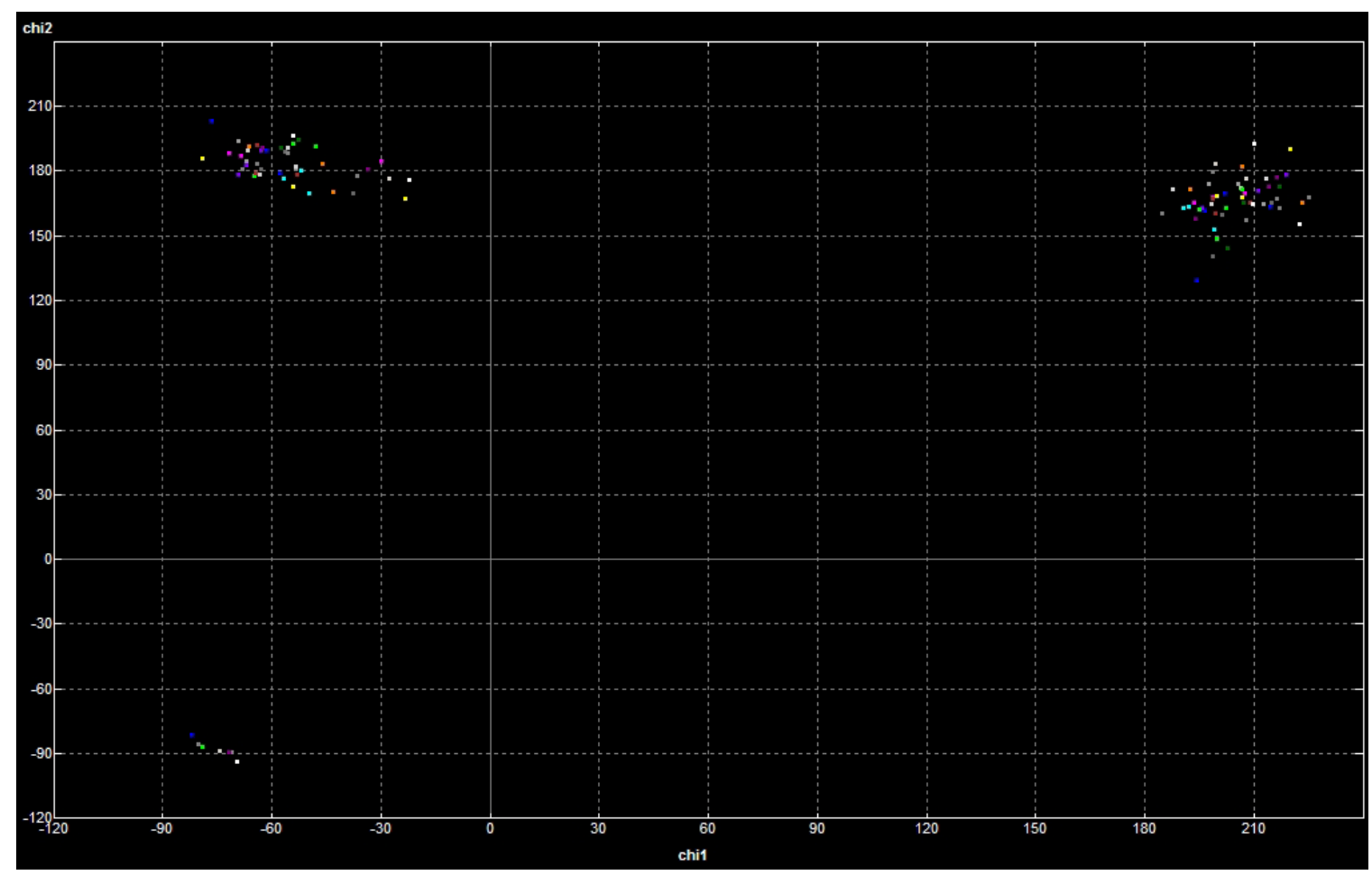

Figure 6: Chi plot for the selected low energy conformations of MD runs. 


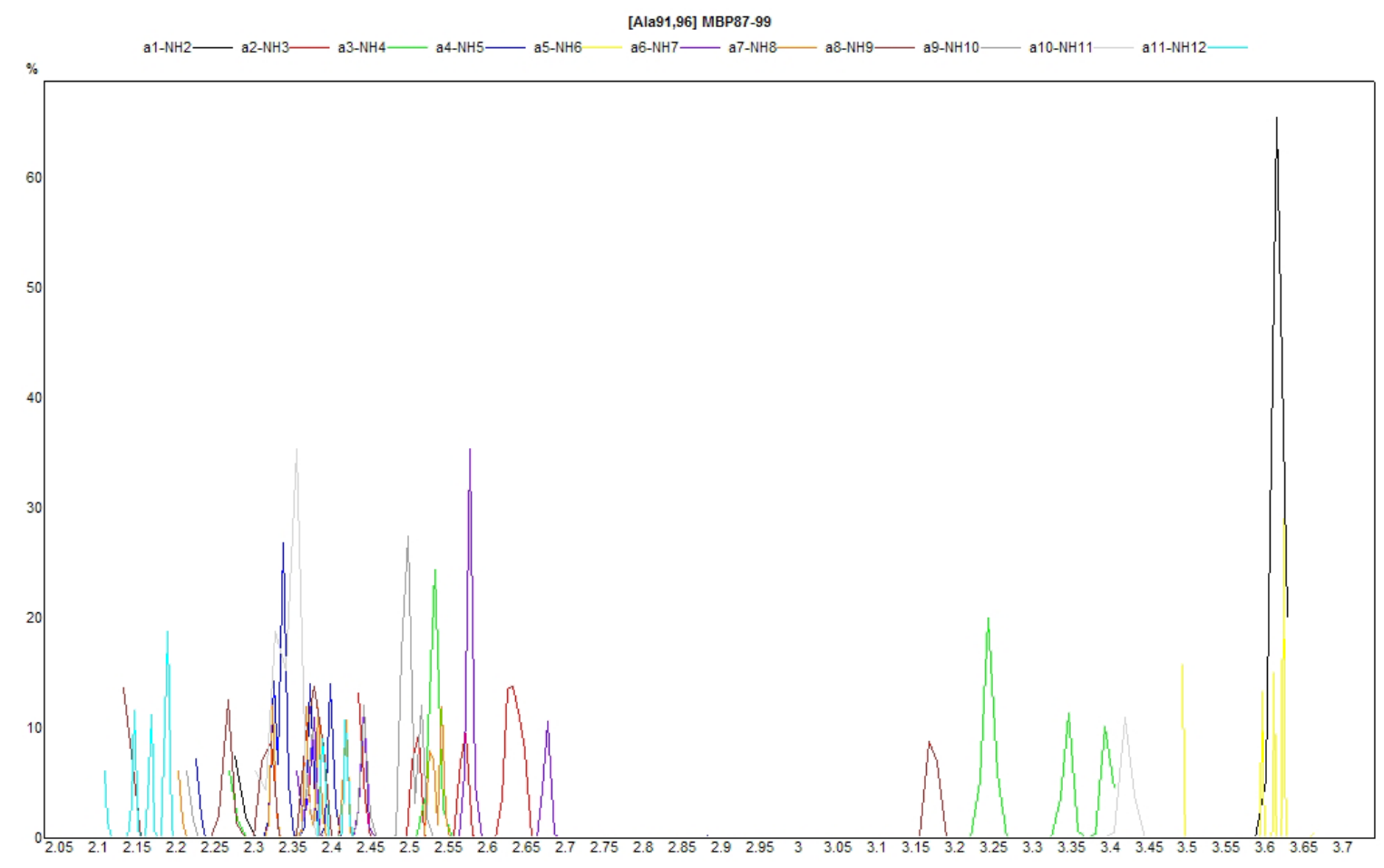

Figure 7: Distances $\mathrm{d}_{\alpha \mathrm{N}(i, i+1)}$ for the selected low energy conformations of MD runs. The values in each case were bucketed, and the number of counts per bucket was plotted. Values were normalized to correct for sample size and the results are displayed in percent. Percentages mentioned refer to the overall number of the selected structures.

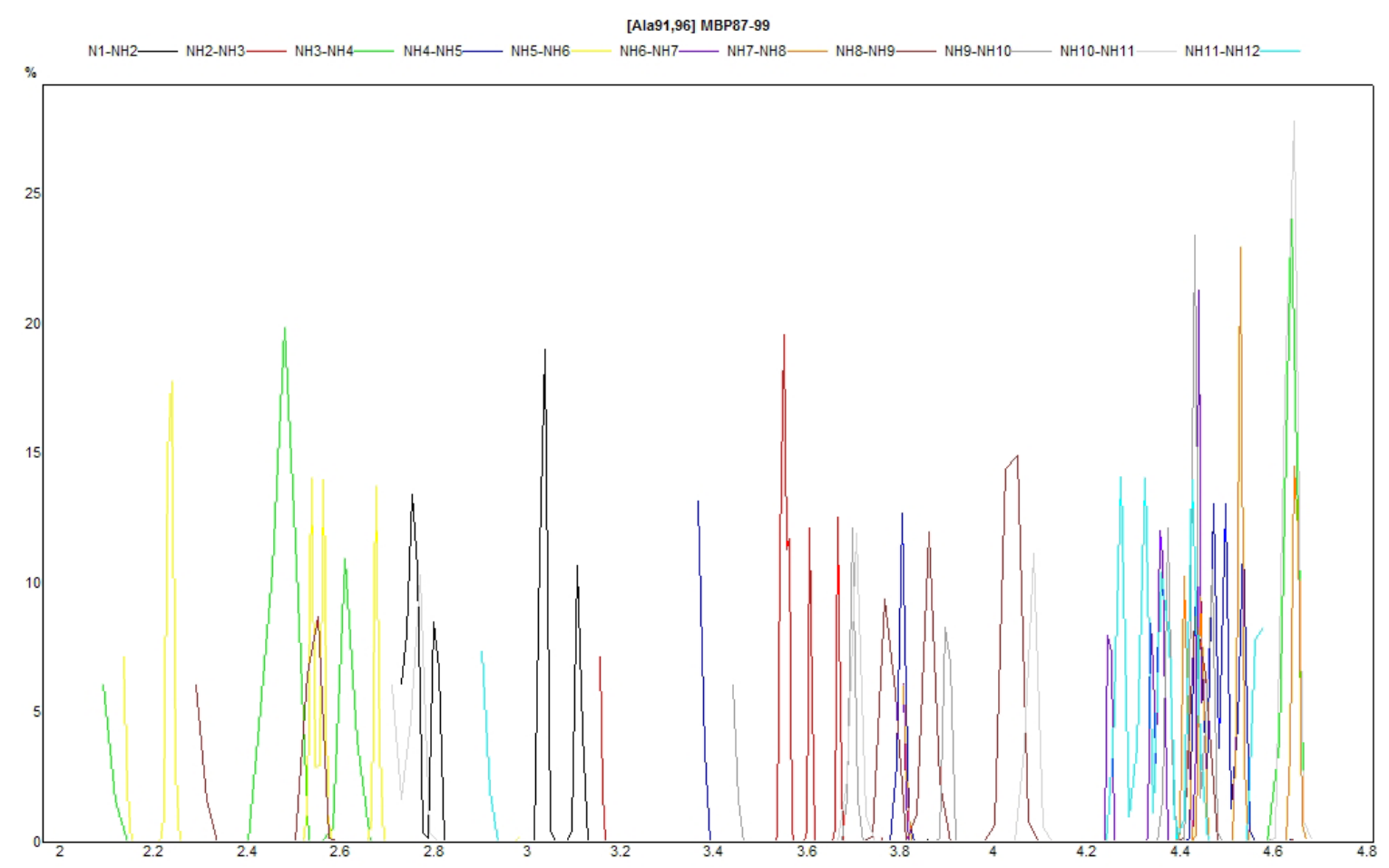

Figure 8: Distances $\mathrm{d}_{\mathrm{NN}(i, i+1)}$ for the selected low energy conformations of MD runs. 


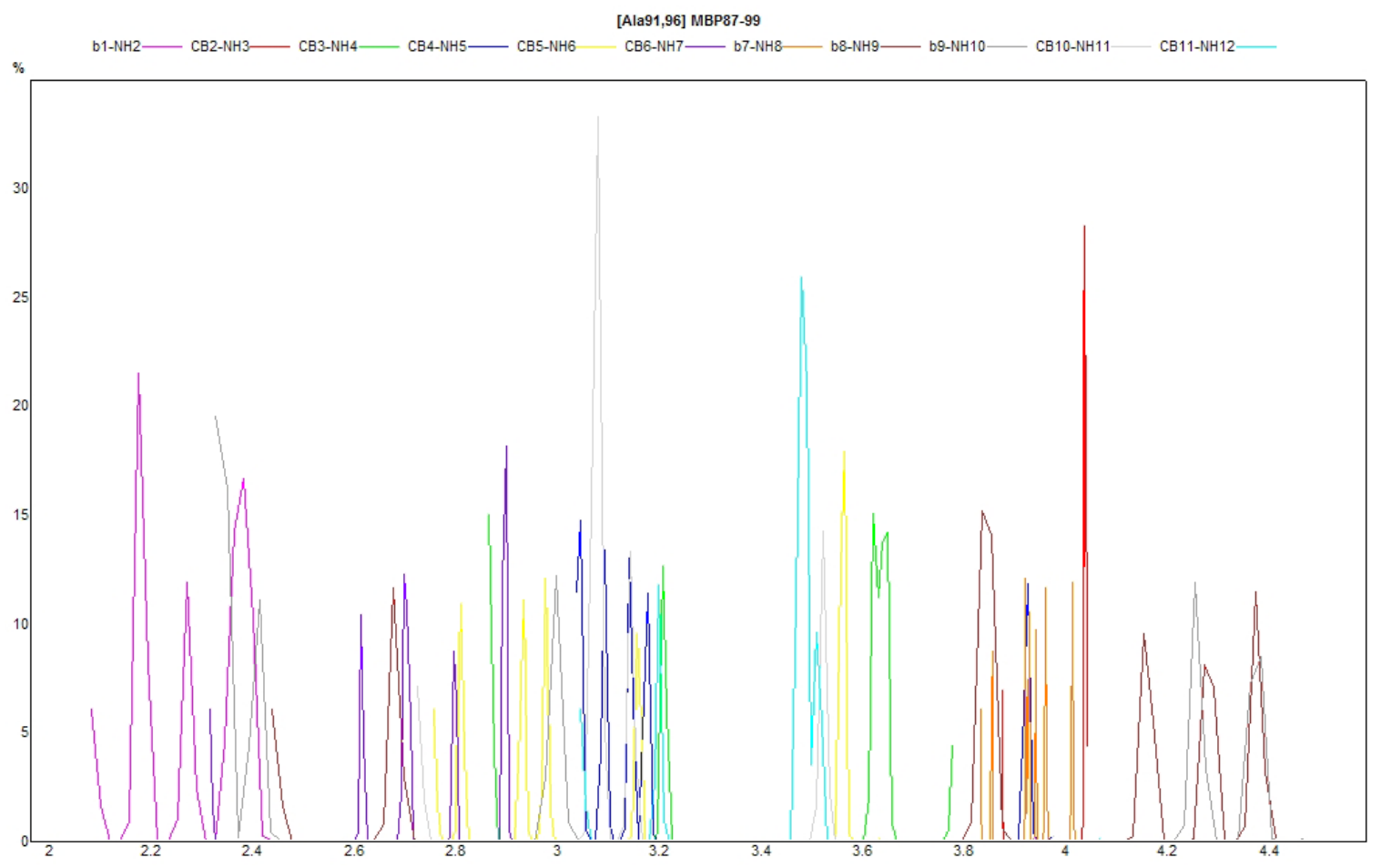

Figure 9: Distances $d_{\beta N(i, i+1)}$ for the selected low energy conformations of MD runs.

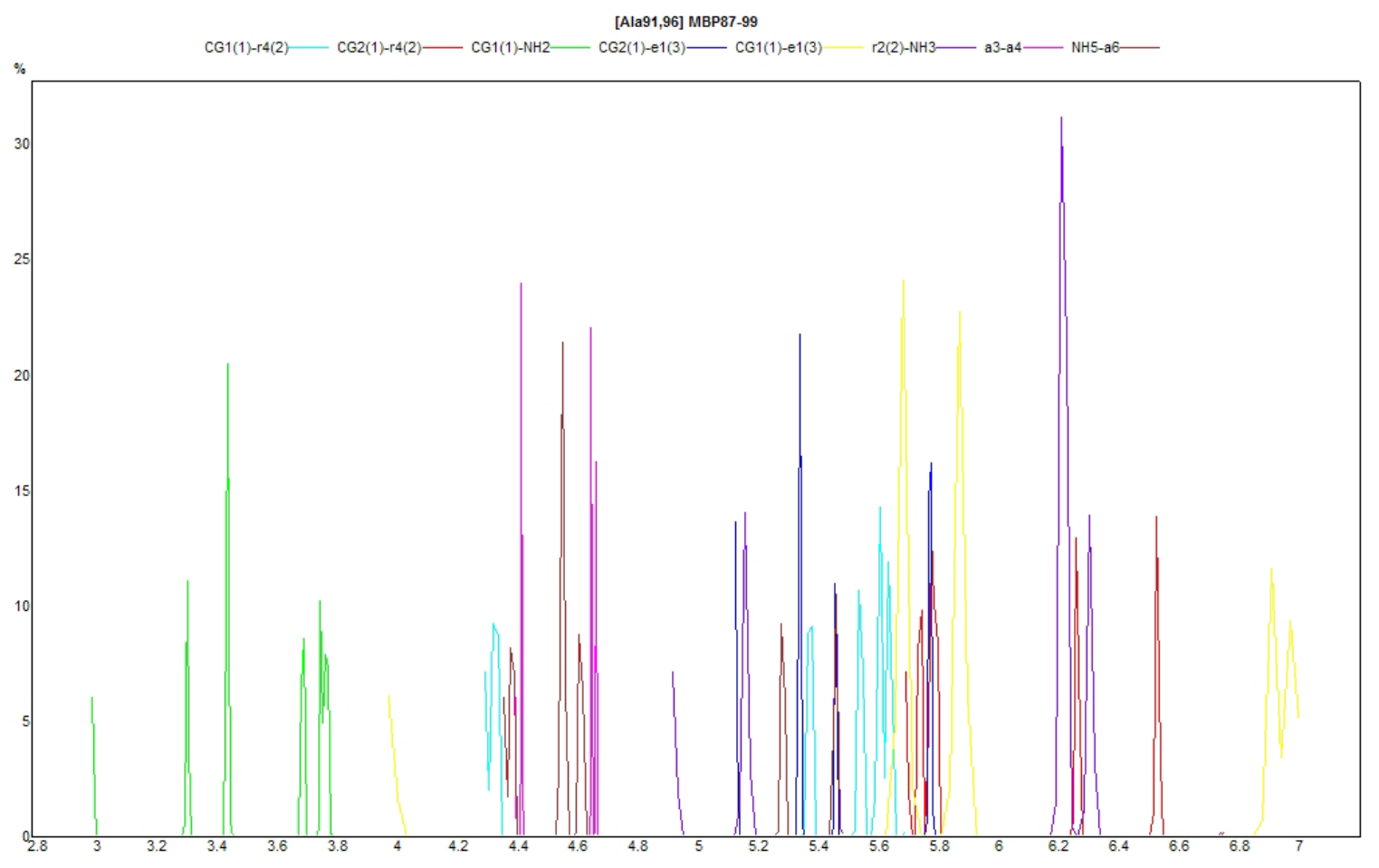

Figure 10: Measured distances for the selected low energy conformations of MD runs.

S - 8 


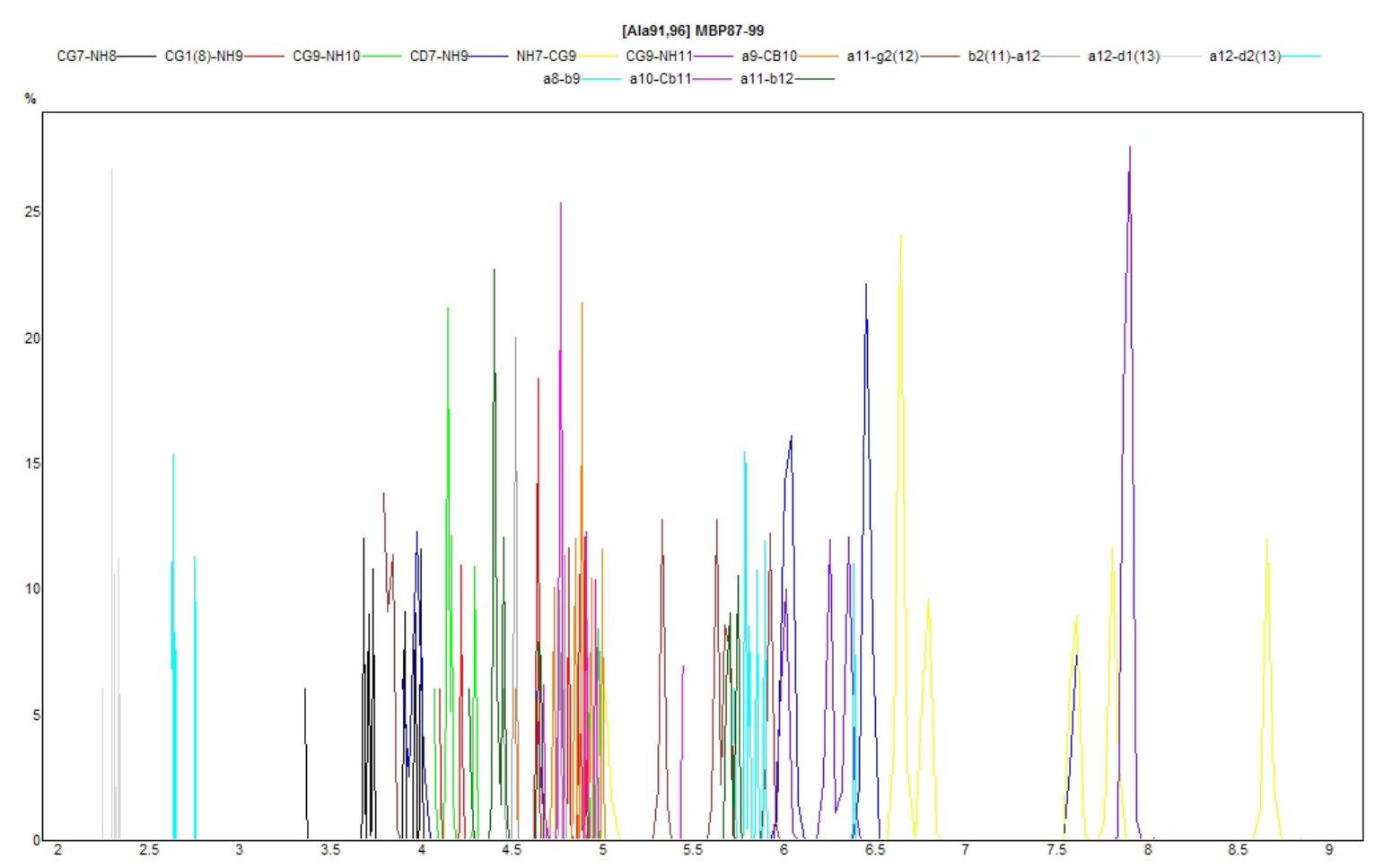

Figure 11: Measured distances for the selected low energy conformations of MD runs.

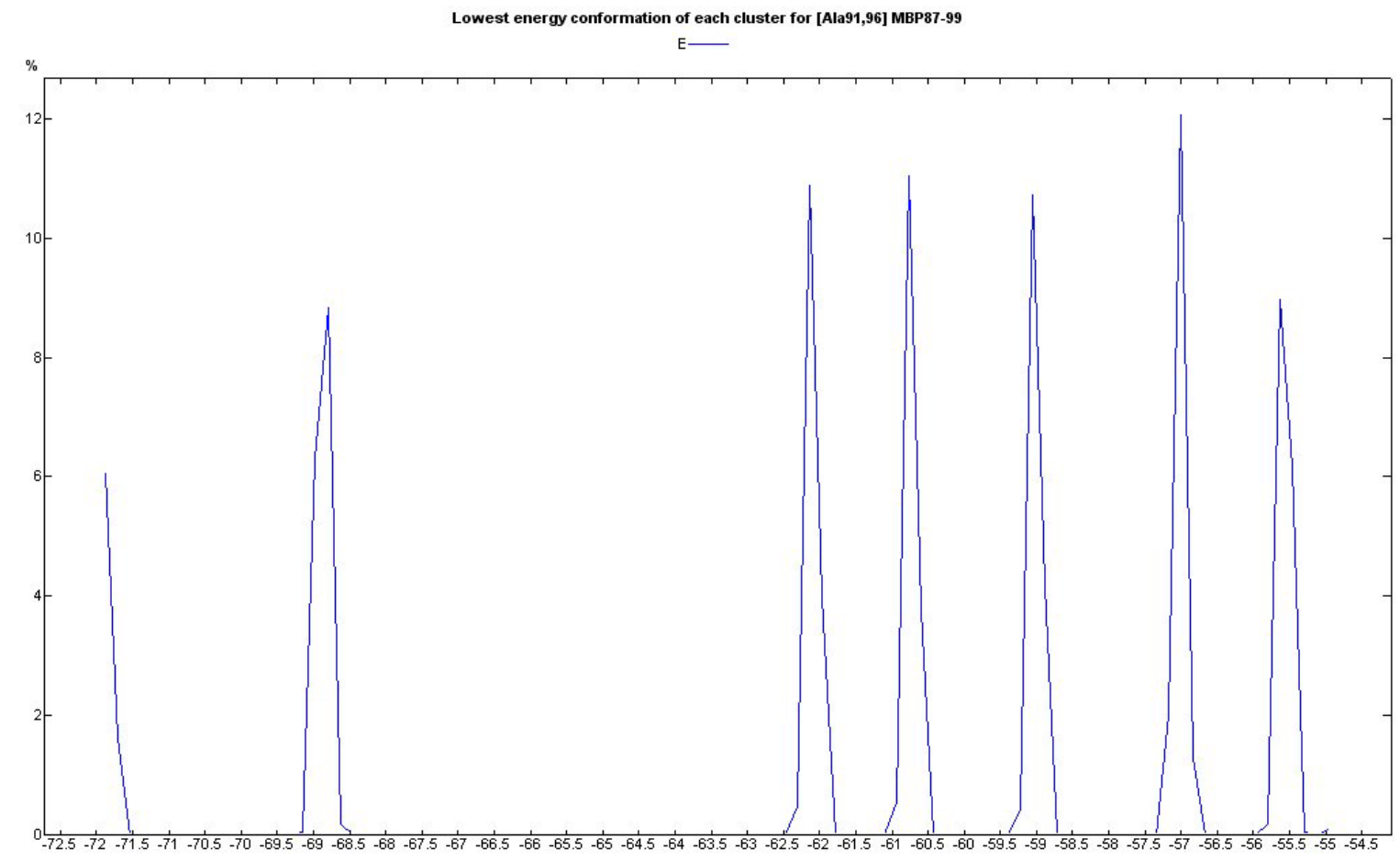

Figure 12: Measured energies for the selected low energy conformations of MD runs. 


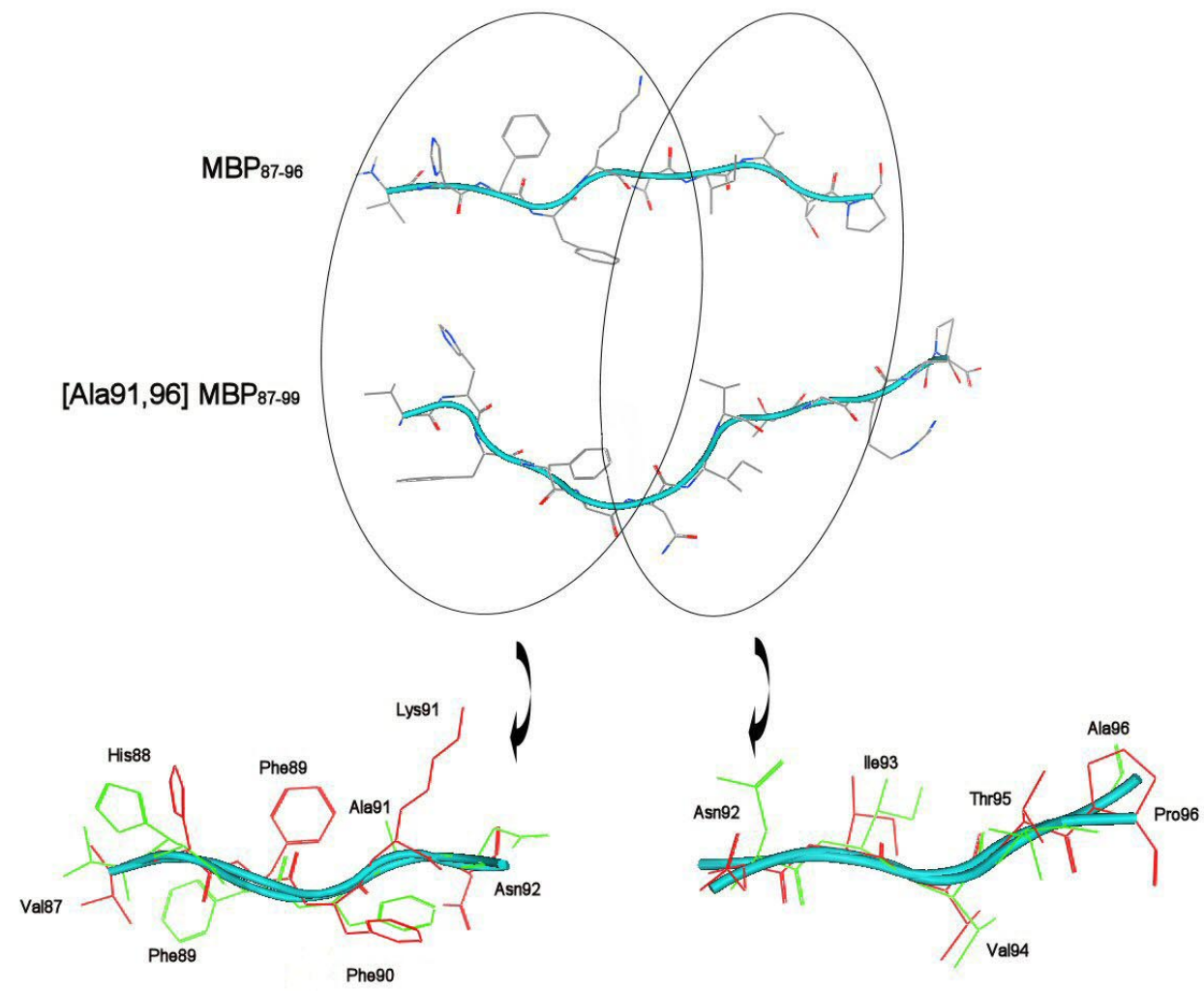

Figure 13: Superimposition between $\mathrm{MBP}_{87-96}$ (red) obtained from the crystal structure (pdb code $1 \mathrm{ymm}$ ) and the proposed bioactive conformation of [Ala $\left.{ }^{91,96}\right] \mathrm{MBP}_{87-99}$ (green). The backbone of both peptides is represented as a cartoon. Two different segments are used for the superimposition, to show agreement with the first two criteria set for bioactivity: residues $87-91$ (left $-\mathrm{C}_{\alpha}$ RMSD: $0.74 \AA$ ) and residues 92 - 96 (right $-\mathrm{C}_{\alpha}$ RMSD: $0.85 \AA$ ). The important part for binding with MHC is that primary MHC anchors $\left(\mathrm{Val}^{87}, \mathrm{Phe}^{90}\right)$ occupy the same space. On the other hand, primary TCR contact Phe ${ }^{89}$ has a notably different orientation between the two structures. 


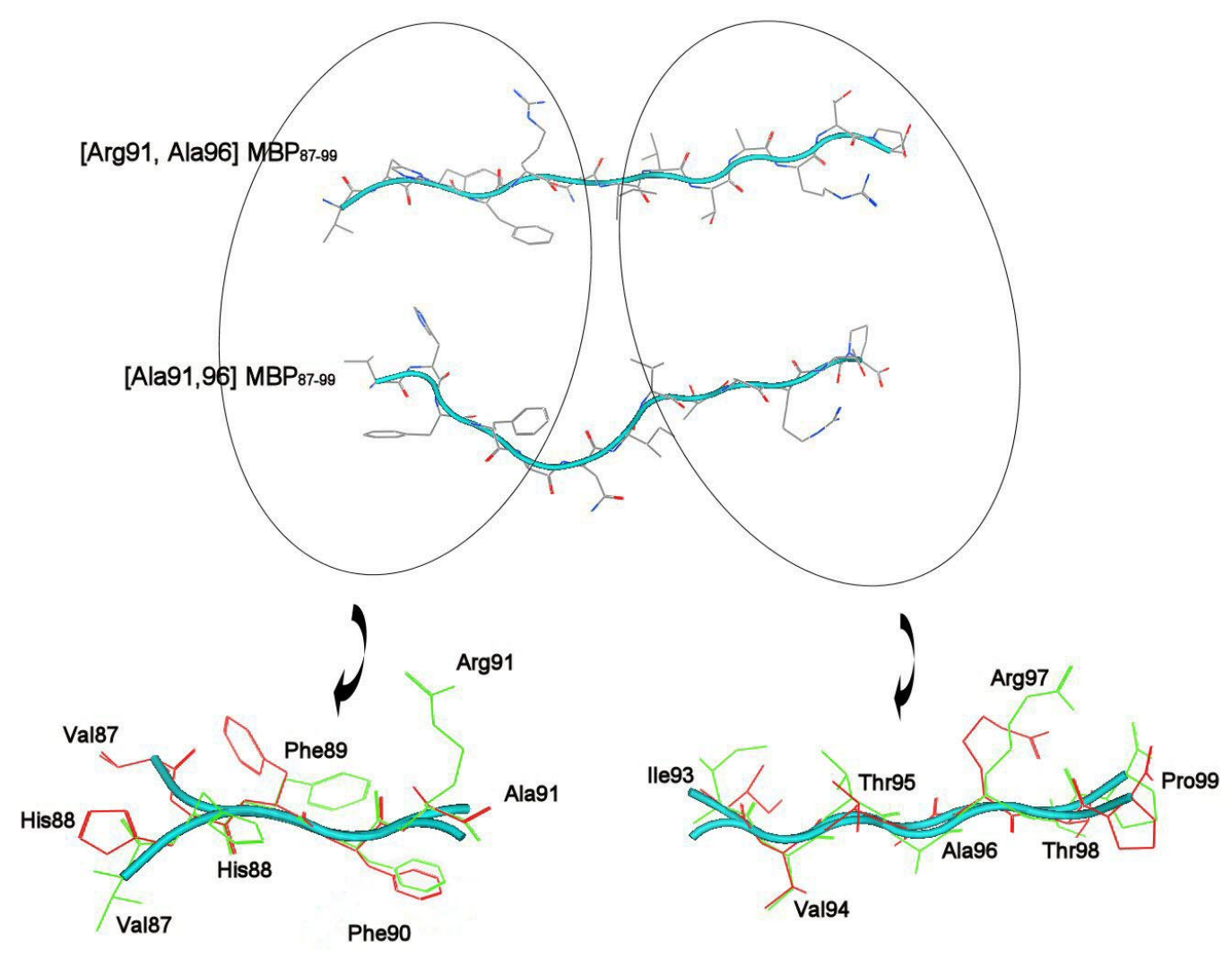

Figure 14: Two different superimpositions between the proposed putative bioactive conformations of $\left[\mathrm{Arg}^{91}, \mathrm{Ala}^{96}\right] \mathrm{MBP}_{87-99}$ (green) and $\left[\mathrm{Ala}^{91,96}\right] \mathrm{MBP}_{87-99}$ (red). The backbone of both peptides is represented as a cartoon. Residues 88-90 (left - $\mathrm{C}_{\alpha}$ RMSD is 0.21 $\AA$ ) and residues 93-98 (right - $\mathrm{C}_{\alpha}$ RMSD is $0.88 \AA$ ). Despite the difference, caused by the substitution of $\mathrm{Arg}^{91}$ with $\mathrm{Ala}^{91}$, the distance between primary $\mathrm{MHC}$ anchors $\mathrm{Val}^{87}$ and $\mathrm{Phe}^{90}$ remains relatively stable in both molecules: $\mathrm{d}_{\mathrm{C} \beta-\mathrm{C} \beta}$ $\left(\mathrm{Val}^{87}-\mathrm{Phe}^{90}\right)$ is $10.83 \AA$ in $\left[\mathrm{Arg}^{91}, \mathrm{Ala}^{96}\right] \mathrm{MBP}_{87-99}$ and $11.31 \AA$ in $\left[\mathrm{Ala}^{91,96}\right] \mathrm{MBP}_{87-99}$. The same distance is $10.80 \AA$ in the native peptide. 


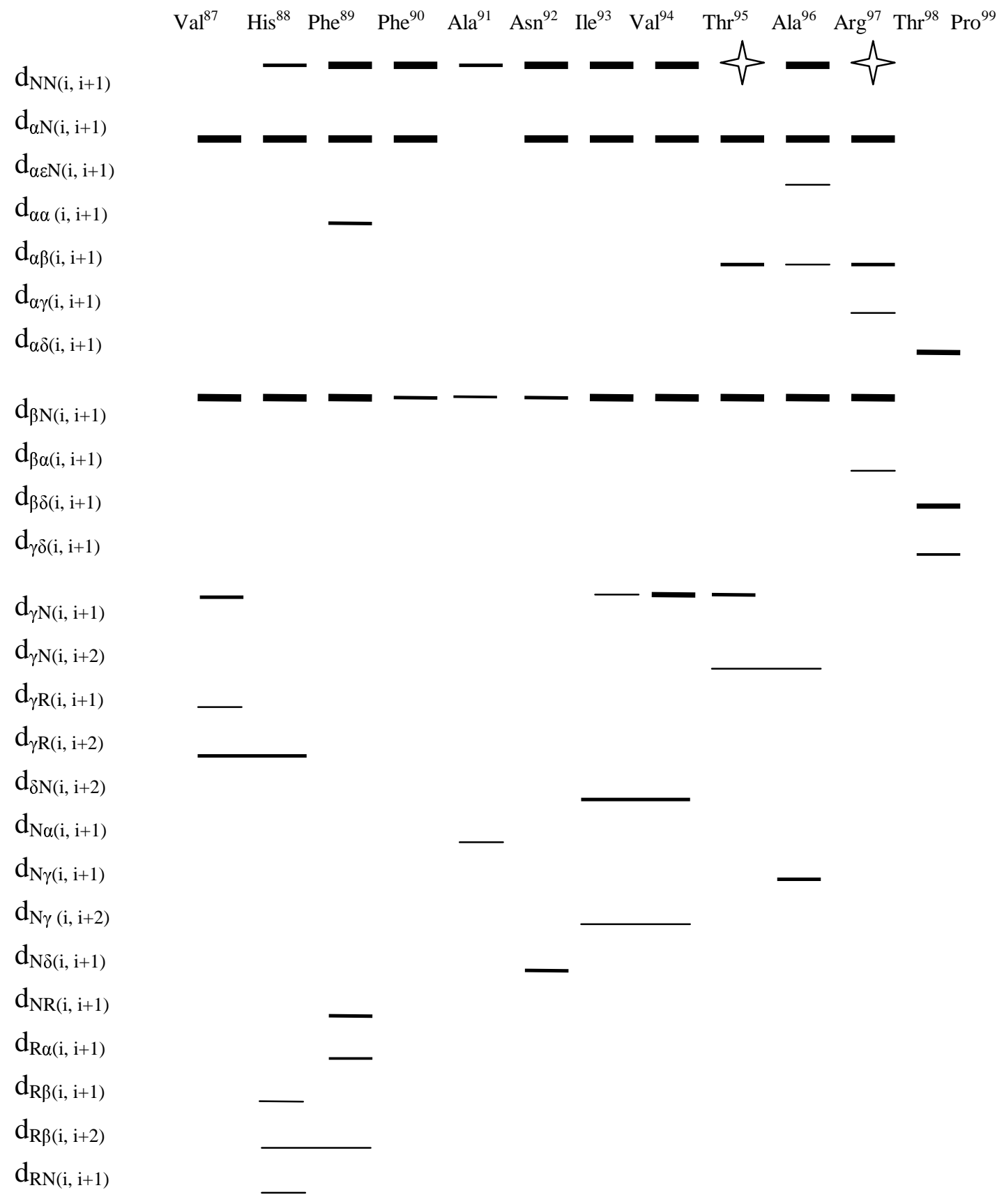

Table 1: Observed inter-residue cross peaks that can only be assigned to one pair of protons in the NOESY spectrum, and their intensities. R refers to the ring hydrogen atoms of the amino acids Phe ${ }^{89}$ and $\mathrm{Phe}^{90}$.

$\checkmark$ Overlap with diagonal

- Weak $(3.8-5 \AA)$

- $\operatorname{Medium}(2.8-3.8 \AA)$

— $\quad$ Strong (up to $2.8 \AA$ ) 


\begin{tabular}{l|lllllllllll}
\hline & $\mathrm{d}_{\mathrm{NN}}$ & $\mathrm{d}_{\mathrm{NN}}$ & $\mathrm{d}_{\mathrm{NN}}$ & $\mathrm{d}_{\mathrm{NN}}$ & $\mathrm{d}_{\mathrm{NN}}$ & $\mathrm{d}_{\mathrm{NN}}$ & $\mathrm{d}_{\mathrm{NN}}$ & $\mathrm{d}_{\mathrm{NN}}$ & $\mathrm{d}_{\mathrm{NN}}$ & $\mathrm{d}_{\mathrm{NN}}$ & $\mathrm{d}_{\mathrm{NN}}$ \\
\hline $\mathbf{1}$ & $\mathrm{S}$ & $*$ & $*$ & & $*$ & & & & $\mathrm{~W}$ & & $\mathrm{~W}$ \\
$\mathbf{2}$ & $\mathrm{M}$ & $*$ & $*$ & & $*$ & & & $*$ & $\mathrm{~W}$ & $*$ & $\mathrm{~W}$ \\
$\mathbf{3}$ & $\mathrm{S}$ & $*$ & & $*$ & $*$ & & & & $\mathrm{~W}$ & $\mathrm{~W}$ \\
$\mathbf{4}$ & $\mathrm{M}$ & $*$ & & & $*$ & & & & $\mathrm{M}$ & & $\mathrm{W}$ \\
$\mathbf{5}$ & $\mathrm{M}$ & $*$ & & $*$ & $*$ & & & & $\mathrm{M}$ & $*$ & $\mathrm{~S}$ \\
$\mathbf{6}$ & $\mathrm{W}$ & $*$ & $*$ & & $*$ & & & & $\mathrm{~W}$ & $\mathrm{~W}$ \\
$\mathbf{7}$ & $\mathrm{S}$ & $*$ & $*$ & & $*$ & $*$ & $*$ & & $\mathrm{~W}$ & \\
$\mathbf{8}$ & $\mathrm{S}$ & $*$ & $*$ & $*$ & $*$ & & & $*$ & $\mathrm{~W}$ & & $\mathrm{~W}$ \\
\hline
\end{tabular}

Table 2: Average $\mathrm{dNN}(\mathrm{i}, \mathrm{i}+1)$ distances were measured for different clusters obtained by molecular dynamics simulations. When direct comparison with calculated total volumes of NOE cross peaks was not possible due to strong overlapping with the diagonal, then distances were classified into three categories: $\mathrm{S}$ (strong) refers to distances smaller than $2.8 \AA, \mathrm{M}$ (medium) is used for distances 2.8 - 3.8 $\AA$, and W (weak) for distances ranging from 3.8 to $5.5 \AA$. In the rest of the cases a direct comparison could be achieved. All the comparative distances that are in agreement with the NMR derived distances are indicated with the symbol asterisk $(*)$.

\begin{tabular}{|c|c|c|c|c|c|c|c|c|c|c|c|}
\hline & $\begin{array}{l}\mathrm{d}_{\alpha \mathrm{N}} \\
(87,88)\end{array}$ & $\begin{array}{l}\mathrm{d}_{\alpha \mathrm{N}} \\
(88,89)\end{array}$ & $\begin{array}{l}\mathrm{d}_{\alpha \mathrm{N}} \\
(89,90)\end{array}$ & $\begin{array}{l}\mathrm{d}_{\alpha \mathrm{N}} \\
(90,91)\end{array}$ & $\begin{array}{l}\mathrm{d}_{\alpha \mathrm{N}} \\
(91,92)\end{array}$ & $\begin{array}{l}\mathrm{d}_{\alpha \mathrm{N}} \\
(92,93)\end{array}$ & $\begin{array}{l}\mathrm{d}_{\alpha \mathrm{N}} \\
(93,94)\end{array}$ & $\begin{array}{l}\mathrm{d}_{\alpha \mathrm{N}} \\
(94,95)\end{array}$ & $\begin{array}{l}\mathrm{d}_{\alpha \mathrm{N}} \\
(95,96)\end{array}$ & $\begin{array}{l}\mathrm{d}_{\alpha \mathrm{N}} \\
(96,97)\end{array}$ & $\begin{array}{l}\mathrm{d}_{\alpha \mathrm{N}} \\
(97,98)\end{array}$ \\
\hline 1 & & $*$ & & $*$ & $*$ & $*$ & $*$ & $*$ & $*$ & $*$ & $*$ \\
\hline 2 & & $*$ & & $*$ & $*$ & $*$ & $*$ & & $*$ & & $*$ \\
\hline 3 & & $*$ & $*$ & $*$ & $*$ & $*$ & $*$ & $*$ & $*$ & $*$ & $*$ \\
\hline 4 & & $*$ & $*$ & $*$ & $*$ & $*$ & $*$ & $*$ & $*$ & $*$ & $*$ \\
\hline 5 & & $*$ & $*$ & $*$ & $*$ & $*$ & $*$ & $*$ & & & \\
\hline 6 & $*$ & & & $*$ & & $*$ & $*$ & $*$ & $*$ & $*$ & $*$ \\
\hline 7 & & $*$ & & $*$ & $*$ & & & $*$ & $*$ & $*$ & $*$ \\
\hline 8 & & $*$ & & $*$ & $*$ & $*$ & $*$ & & $*$ & $*$ & $*$ \\
\hline
\end{tabular}

Table 3: Average $\mathrm{d}_{\alpha \mathrm{N}(i, i+1)}$ distances were measured for different clusters obtained by molecular dynamics simulations. Symbol asterisk (*) indicates accordance with NOE sequential connectivities obtained from the NMR data. 


\begin{tabular}{l|lllllllllll}
\hline & $\mathrm{d}_{\gamma 1 \mathrm{r} 4}$ & $\mathrm{~d}_{\gamma 1 \mathrm{~N}}$ & $\mathrm{~d}_{\gamma 2 \varepsilon 1}$ & $\mathrm{~d}_{\mathrm{r} 4 \mathrm{~N}}$ & $\mathrm{~d}_{\alpha \alpha}$ & $\mathrm{d}_{\mathrm{N} \alpha}$ & $\mathrm{d}_{\gamma \mathrm{N}}$ & $\mathrm{d}_{\delta \mathrm{N}}$ & $\mathrm{d}_{\mathrm{N} \gamma}$ & $\mathrm{d}_{\gamma \mathrm{N}}$ & $\mathrm{d}_{\gamma \mathrm{N}}$ \\
& $(87,88)$ & $(87,88)$ & $(87,89)$ & $(88,89)$ & $(89,90)$ & $(91,92)$ & $(93,94)$ & $(93,95)$ & $(93,95)$ & $(94,95)$ & $(95,96)$ \\
\hline $\mathbf{1}$ & $*$ & $*$ & $*$ & & $*$ & $*$ & $*$ & & & $*$ & $*$ \\
$\mathbf{2}$ & & $*$ & & & $*$ & $*$ & $*$ & $*$ & & $*$ & $*$ \\
$\mathbf{3}$ & & $*$ & $*$ & & $*$ & $*$ & $*$ & & $*$ & $*$ & $*$ \\
$\mathbf{4}$ & $*$ & $*$ & $*$ & $*$ & $*$ & $*$ & $*$ & & $*$ & $*$ & $*$ \\
$\mathbf{5}$ & & $*$ & $*$ & & $*$ & & & & $*$ & $*$ & $*$ \\
$\mathbf{6}$ & $*$ & $*$ & $*$ & $*$ & $*$ & $*$ & $*$ & & & $*$ & $*$ \\
$\mathbf{7}$ & & $*$ & & & $*$ & $*$ & $*$ & $*$ & & $*$ & $*$ \\
$\mathbf{8}$ & & $*$ & & & $*$ & $*$ & $*$ & $*$ & & $*$ & $*$ \\
\hline
\end{tabular}

Table 4: Average measured distances for different clusters obtained by molecular dynamics simulations. Symbol asterisk $(*)$ indicates accordance with NOE connectivities obtained from the NMR data.

\begin{tabular}{l|llllllll}
\hline & $\mathrm{d}_{\alpha \beta(95,96)}$ & $\mathrm{d}_{\gamma \mathrm{N}(95,97)}$ & $\mathrm{d}_{\alpha \beta(96,97)}$ & $\mathrm{d}_{\alpha \beta(97,98)}$ & $\mathrm{d}_{\alpha \gamma(97,98)}$ & $\mathrm{d}_{\beta \alpha(97,98)}$ & $\mathrm{d}_{\alpha \dot{\delta} 198,99)}$ & $\mathrm{d}_{\alpha \delta 2(98,99)}$ \\
\hline $\mathbf{1}$ & $*$ & & $*$ & $*$ & $*$ & $*$ & $*$ & $*$ \\
$\mathbf{2}$ & & $*$ & & $*$ & & $*$ & $*$ & $*$ \\
$\mathbf{3}$ & $*$ & $*$ & $*$ & & $*$ & $*$ & $*$ & $*$ \\
$\mathbf{4}$ & $*$ & & $*$ & & $*$ & $*$ & $*$ & $*$ \\
$\mathbf{5}$ & & $*$ & & & & & $*$ & $*$ \\
$\mathbf{6}$ & $*$ & & $*$ & $*$ & $*$ & $*$ & $*$ & $*$ \\
$\mathbf{7}$ & $*$ & & $*$ & $*$ & $*$ & $*$ & $*$ & $*$ \\
$\mathbf{8}$ & $*$ & & $*$ & $*$ & $*$ & $*$ & $*$ & $*$
\end{tabular}

Table 5: Average measured distances for different clusters obtained by molecular dynamics simulations. Symbol asterisk (*) indicates accordance with NOE connectivities obtained from the NMR data. 